\title{
Comparative Analysis and Study of Data Mining Techniques Used for IoT Based Smart Healthcare System
}

\author{
Navita $^{1}$, Pooja Mittal ${ }^{2}$ \\ ${ }^{1} \mathrm{Ph} . \mathrm{D}$ Scholar, Department of Computer Science and Applications, Maharshi Dayanand University Rohtak, \\ Haryana, navitamehra55@gmail.com \\ ${ }^{2}$ Assistant Professor, Department of Computer Science and Applications, Maharshi Dayanand University \\ Rohtak, Haryana, mpoojmdu@gmail.com
}

\begin{abstract}
Among the broad and excitingset of applications empowered by the Internet of Things (IoT), Healthcare is the most interactive one. Smart healthcare is apioneering procedure of synergizing the benefits of the Internet ofThings (IoT), sensors, and large data analysis to convey better healthcare services with reduced costs. Asignificant aspect of the study in such a framework is how to treat and handle the data. This paper gives acomaprative analysis and a current reviewof themost recent techniques and algorithms used to analyze the data generated from wearable sensors utilized for physiological observation of crucial symptom in the patients. The paper starts withabrief introduction of the idea ofIoT in the healthcare domain alongwith the rising requirementfor data mining techniques in this domain. It also provides a detailed study ofdiverse data mining techniques and algorithms utilizedby different researchers for accurate identification of diseases. In last, based on the literature study a comparative analysisof different data mining techniques used for diagnosis of diseases like diabetes, heartdisease, Parkinson, liver disorder, hypertension, etc. is made. This will take attention in the direction of the set of data mining techniques and tools that are highly useful for the analysis of different diseases and for making decision process accordingly.
\end{abstract}

Keywords- IoT, Healthcare, Data Mining Techniques (DMT), SVM, KNN, Naïve Bayes, Decision Tree (DT), $\mathrm{KDD}$, Artificial Intelligence (AI)

\section{INTRODUCTION}

The Internet of Things (IoT) is the latest technology that dramatically changesour way of life and rapidly accepted by the real world in most of the areas like smart hospitals, smart parking, smart agriculture,IT, and manufacturing industries. Internet of Things (IoT) is a new technology that seamlessly integrates a classical network of objects in our surroundings. With the emergence of IoT all the things connected to the network having the capability of automatic sensing, talking, and also having the capability to take decisions by themselves. It is expected that at the end of the year 2020, 20 billion devices would be connected to the IoT [1].

A large portion of these connected devices isfrom healthcare. Providingbetter healthcare services can be counted as one of the foremost challenge of today's word. It is estimated that approximatelya 20-30 billion population of this worldsuffering from chronic diseases like asthma, heart attack,diabetes, cancer, HIV/AIDS, Alzheimer, obesity, stroke,mental health illness, etc[2]. Indulgmentof IoT concept into the healthcare sector becomes very advantageous for both the caregivers and the patients.In terms of healthcare the "Things" in the Internet of Things (IoT) means a wide variety of medical devices such as insulin pumps, pacemakers, apple watch and fit bit band etc. which may be wearable or implanted on patients body[4][38] from which data must be collected for analysis.

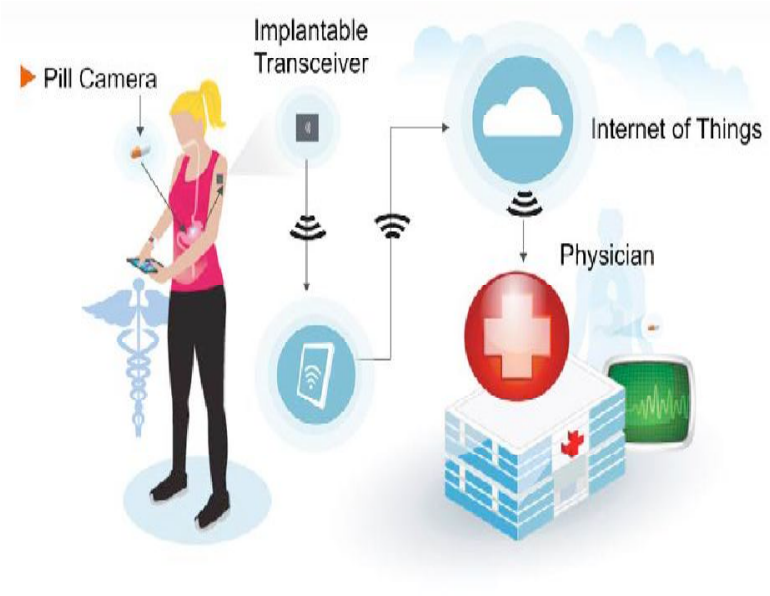

Figure 1: Remote Patient Monitoring

Generally, a question arises that is "How do we change the data generated or captured by IoT into knowledge to give a more convenient environment to the individuals?" [11][12][13]. Duetothis reason knowledge discovery in databases(KDD) and data mining techniques come into play to providean adequate solution by finding the hidden information from the data of IoT. This newly generated information can be used to enhance the quality of services and performance of the system. A lot of research work has been done on the use and development of effective data mining techniques and algorithms for the IoT in different fields such as smart parking, smart cit, healthcare and agriculture, e-commerce, industry, etc. The study of different papers proves that data mining techniques play an important role to make the IoT more smart and intelligent in providing their services. 
Navita et al., International Journal of Emerging Trends in Engineering Research, 8(9), September 2020, 6131 - 6138

Table 1: IoT based applications of Data Mining Techniques

\begin{tabular}{|l|c|c|c|c|}
\hline $\begin{array}{l}\text { Data Mining } \\
\text { Techniques }\end{array}$ & Smart Industry & Smart Healthcare & E-commerce & Smart City \\
\hline Classification & $\checkmark$ & $\checkmark$ & $\checkmark$ & $\checkmark$ \\
\hline Clustering & $\checkmark$ & $\checkmark$ & $\checkmark$ & $\checkmark$ \\
\hline Association Analysis & $\checkmark$ & $\mathbf{x}$ & $\checkmark$ & $\checkmark$ \\
\hline Outlier Analysis & $\mathbf{x}$ & $\checkmark$ & $\checkmark$ & $\mathbf{x}$ \\
\hline
\end{tabular}

This paper mainly concerned with the data mining techniques and algorithms used in the healthcare domain. As everyone knows the healthcare domain is basically "datarich" as a lot of data regarding patient health generated daily and to make a proper decision regarding patient health some data mining techniques and algorithms must be applied to reach at a particular decision and to take an attentive action on that. This paper gives description about the various data mining techniques and algorithms utilized in healthcare field connected with IoT but also describes the problems faced by the healthcare sector in the diagnosis of diseases and how data mining techniques help in solving these problems. This paper also provides comparisons of different data mining techniques used by different researchers in this field on the basis of different factors. The Road map of this paper is organized assection 1 starts with a brief introduction about IoT, its different area of application, followed by an inspiration towards applying data mining techniques and algorithms to the IoT in the healthcare domain. A lietrature study about the work done by different researchers is done in section 2. Section 3 gives a detailed description of the various data mining techniques used in IoT based healthcare domain.Section 4 provides the comparative analysis. In last, Conclusion and future works are drawn.

\section{LITERAURE STUDY ON WORK DONE BY DIFFERENT RESEARCHERS}

P. K. N. Anooj [09] proposed a clinical decision support system (CDSS) based on a weighted fuzzy rule for heart diseases diagnosis. The proposed system obtain knowledge from patient's clinical data. Finally, the experiment was performed on UCI data. After experimentation, the outcome ensured that the proposed system having enhanced performance, sensitivity, and specificity as compared to network based system.

Chiuchisan and Geman [33] described the procedure of how an integrated intelligent system developed for the screening of Parkinson's diseases. They designed aHome monitoring and decision support system in order to support and sustain physicians in the diagnosis, home monitoring, and providing medical treatment to the patients suffering from Parkinson's diseases.

P.D. Kaur and I. Chana [17] designed a system that supports a real-time monitoring of Patient's health data for the diagnosis of chronic illness such as diabetes and named it as Cloud-Based Intelligent Health Care Service (CBIHCS). They utilized the sophisticated body sensor components in order to

collect health data specific to user and store it on the cloud for consequent analysis and classification of the diseases.
With the help of CBIHCS, a cost-effective globally available and highly converged health care solution can be easily achieved.

Sanjay Sareen et al.[32] proposed anew architecture by using the concept of Radio Frequency Identification Device (RFID),

cloud computing infrastructure and wearable sensor technology for the recognition and monitoring of patients infected from Ebola-virus. The major aim of their work is to prevent the spreading of the infection of Ebola virus at the early stage of the outbreak. In order to evaluate the level of infection in a patient on the basis of his symptoms J48 decision tree is used. Amazon EC2 cloud is used to evaluate the performance and accuracy of the proposed model.

Hossian\& Muhammad [14] presented a Health IIoT-enabled monitoring framework, where patient's data are collected through sensors and mobile devices and data are securely sent to the cloud which can be seamlessly approached by healthcare professionals. In order to offer security services watermarking, signal enhancement, and other related analytics will be performed.

P. Verma et al. [27] proposeda disease diagnosis mhealthcare framework using the concept of cloud and IoT. The proposed model predicts the potential disease with its level of severity. A variety of classification algorithms are applied for the diagnosis purpose and the results are computed using different performance metrics such as accuracy, specificity, sensitivity, and F-measure.

P.Verma and S. Sood [24] Proposed a cloud-centric IoT based smart student m-healthcare monitoring framework. This framework computes the student disease severity by temporarily mining health measurements collected from medical and other IoT devices.

P.M. Kumar and U.S. Gandhi [18] proposed a three-tier architecture to store and process the huge volume of data generated through sensors. This architecture also identifies the most significant clinical parameters to get heart disease. From their experimental result, they find out that Respiratory Rate (RP) at around 50 and 12 is highly significant which gives an indication of heart disease. Other than that Heart rate 160 and blood Temperature (BT)

140 and 37 also considered as highly significant parameters in indicating heart Diseases.

P.M.Kumar et al. [36] proposed a new cloud and IoT based Mobile Heathcare for observing the patient suffering from diabetic disease. For this purpose they proposed a neural classifier approach using fuzzy rule. They experimented their result on UCI data set and found that the result of their propsed work is better than the existing system used for diabetic disease. 


\section{DATA MINING FOR IOT INSMART HEALTHCARE}

This section mainly describes the relationship between the data generated from various IoT smart devices such as sensors, actuators and the summarization of various data mining techniques used for IoT in the healthcare domain.

\subsection{Essential Idea of utilizing Data Mining for IoT in Smart Healthcare}

IoT is one of the major technological advancementwhich has included the component of "smartness" in the healthcare system[6][7][23][37]. A smart healthcare system utilizesa variety of sensors and medical devices to gatherdata regarding patient health.Thesebiomedical sensors are either wearable or embeddedinthe patient body to collect the data as shown in figure 2 .

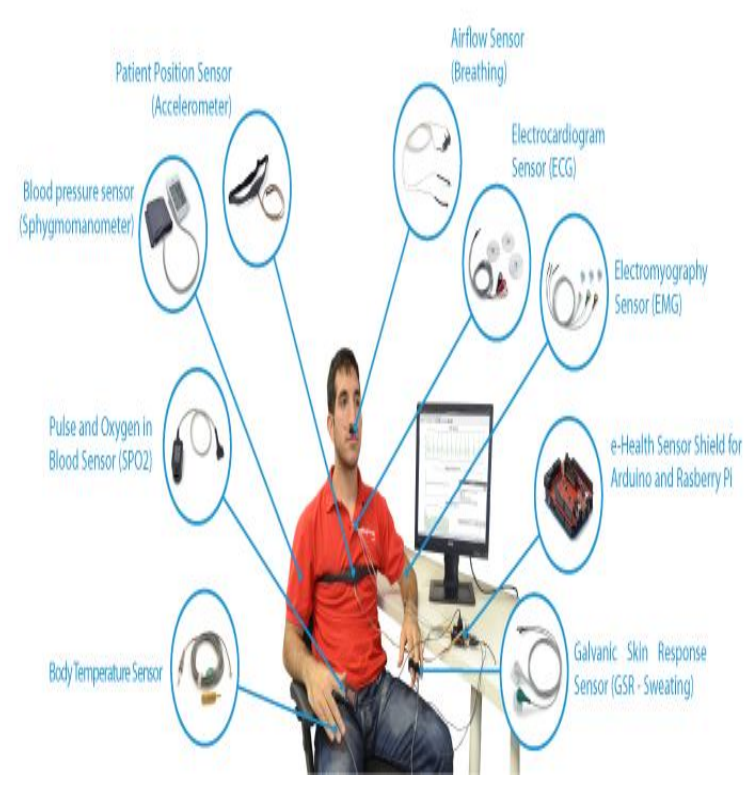

Figure 2: Diverse Biomedical Sensors [40]

A vast amount of data is originated through these biomedical sensors and for better analysis and diagnosis of the disease,there may happen a need of designing the data mining techniques which are highly appropriate for increasing the performance of the system and for finding better services in smart healthcare [6].

\subsection{Significant Challenges of utilizing Data Mining for IoT in Smart Healthcare}

When applying data mining in this area a lot of challenges are faced which are described beneath:

- One of the major challenge is to extract huge data existing in diverse data storage and to detect any noise or defective data in that large data set.

- Mining vague and imperfect data is also abig challenege

- Modification of algorithms is also a very difficult challenge.
- Providing safety and confidentiality services for shared data is also a big challenge

- Analysis and management of huge data is also a complicated task for data mining

- Selection and implementation of better\& efficient technology and mapping it with other technology is a complex task.

\subsection{Data Mining Techniques utilized in IoT based Smart} Healthcare System

In the healthcare domain, data mining techniques are mainly used for disease diagnosis purposes.Various diseases are heartily associated with a symptom which makes it problematical for the specialists to forecast the exact diseases from which one is suffering. Data mining techniques help in forecasting the disease which is exactly perfect.

Basically data miming techniques are separated into two categories as supervised and unsupervised learning [6][7][23].Supervised learning uses a training data setthat having a suitable target attribute and based on this training data set, algorithms answerexactly to all feasible inputs that are applied to it. It is also named as learning from Examples.Unsupervised learning finds out the hidden structure from unlabeled data. It first finds out the similarities among the input data and classifies the data on the basis of their similarities [23].

Majorly classification techniques which come under supervised learning used in the healthcare domain for better forecasting of the diseases. Major classification techniques are described below :

- Decision Tree

- K Nearest Neighbour

- Neural Network

- Naive Bayes

- Support Vector Machine

3.3.1 Naive Bayesian: Naive Bayes is a classification technique based on Baye's theorem. This method simply assigns labels to the data whose labels are previously unknown [6][7]. For the classification of data, this method simply applies the Bayes theorem[23]. Baye's theorem states that:

\section{$\mathbf{P}(\mathbf{m} \mid \mathbf{n})=(\mathbf{P}(\mathbf{n} \mid \mathbf{m})) * \mathbf{P}(\mathbf{m})) / \mathbf{P}(\mathbf{n})$}

where $\mathrm{P}(\mathrm{m} \mid \mathrm{n})$ denotes the posterior probability and $\mathrm{P}(\mathrm{n} \mid \mathrm{m})$ denotes the prior probability

$\mathrm{P}(\mathrm{m})$ denotes the probability of the hypothesis being true.

$\mathrm{P}(\mathrm{n})$ denotes the probability of data.

This technique can be applied for the diagnosis of different diseases such as water-born disease, hypertension, ebola virus, diabetes, etc. whose data collected by using different biomedical sensors [17] [24][27]. The major advantage of this method is that it can be applied to the large data set.

3.3.2Decision Tree:Decision tree is a significant algorithm which isbased on branching methodology. It is a consistent technique utilized in the diverse filed of the medical domain in order to make a accurate prediction.

This technique is also appropriate for managementof data generated from multivariate sensors. Many researchers 
applied this technique on the data generated by different sensors such as EmotivEPoc sensor, temperature sensor, blood pressure sensor, blood glucose monitoring etc. for the prediction of various diseases such as heart diseases, breast cancer, hypertension and other chronic illness in IoT based healthcare environment (Prabal Verma et al.[24] , Prabal Verma et al. [27], Sanjay Sreen et al.[ 34] and L.Sayeed et al. [37]). This algorithm is very easy and simple to implement and less frequently applied to complex and big psycological data.

Example of a decision tree used for the diagnosis ofhypertension diseases as shown in figure 3(by Prabal Verma et al. [24]). Blood Pressure Sensor is utilized to measure human blood pressure in form of systolic, diastolic pressure. On the basis of two parameters systolic and diastolic pressure patients are categorized into two classes as normal and hypertension. At first, systolic pressure is checked if systolic pressure $<90$ then check diastolic pressure if diastolic pressure $<60$ then put patient in Hypertension class otherwise again check systolic pressure, if systolic pressure $<120$ put in a normal class and if systolic pressure $<140$ put the patient in hypertension class.

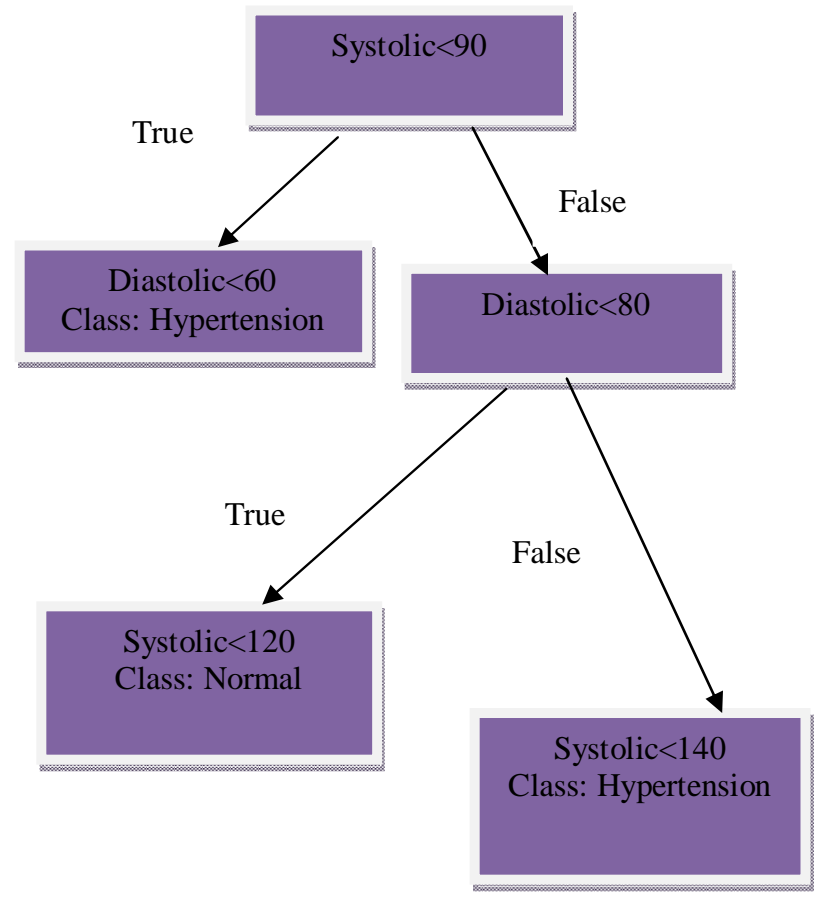

Figure 3: Decision Tree used to classify Patient into Normal and Hypertension Class [24]

3.3.3 Neural Network:It is an artificial intelligence approach commonly utilized for prediction and classification. It is simply a network of neurons [26][22].
The structure and functionality of a neural network issimilar to biological neurons.

Because of theacceptablepredictive performance of the neural network, it becomesthe most admired modelling method used in the medical domain. A wide variety of diseases diagnosis and decision making actions have beenperformed by the neural network in the medical domain.A neural network can also be applied for multisensor networks to handle the complicated analysis of multivariate data.

A Multilayer Perceptron Neural Network (MPNN) used to classify breast cancer disease (by L.Sayed et al. [37]) and find out that MLPNN can be counted as the top classifier for detecting malignant and benign tumorsin patient. Multilayer Perceptron Neural etwork(MPNN) is also used to classify or detect heart disease (by M.Ganisan et al.[35]) by using different IoT technology such as sensors, Bluetooh, Zigbee, smart EGC machine, wearable gadgets,ect.

3.3.4 K-Nearest Neighbor: KNN classification algorithm totally depends upon the distance metric used to recognize the nearest neighbor of the observed object[6][7]. This algorithm is highly useful in the situation where a large amount of historical data is providedtodiagnose the disease. Different researchers work on this algorithm for the diagnosis of various diseases like water born disease, hypertension, breast cancer diagnosis [24][27][37] in the IoT environment with the help of using different sensors and other medical devices.

3.3.5 Support Vector Machine: Support vector machine (SVM) is the best learning method that basedon statistical theory which has the capability to classify hidden information by deriving selected features and construct a hyperplane to divide the data

points into two classes [26]. It having the capability to handle the high dimensional data. ECG, HR, and $\mathrm{SpO} 2$ are the major health parameters that are considered by SVM. One class SVM used to classify heart disease in IoT based health monitoring framework (Hossian and Muhmad[14])by using ECG based monitored sensors. Other resaerchers also use SVM for heart disease detection[24][27][35] and find out that SVM betterly classify ECG signals.

\section{COMPARATIVE ANALYSIS}

The below table 3 shows the comparative analysis of the work done by different researchers in the IoT based smart healthcare environment. The table portrayed that the researchers utilized various data mining techniques for the detection of the diverse diseases on the real-time data means data generated through different sensors and smart medical devices. The table additionaly talked about the tools and platform on which they worked and results of their outcomes when applied for the diagnosis of different diseases. 
Table 3: Comparative Analysis of work done by different researchers

\begin{tabular}{|c|c|c|c|c|c|c|c|}
\hline $\begin{array}{l}\text { Author's } \\
\text { Name }\end{array}$ & Year & $\begin{array}{l}\text { Data Mining } \\
\text { Techniques }\end{array}$ & Sensors / IoT Technology & Diseases & Tools & Findings & $\begin{array}{l}\text { Performance } \\
\text { Metrics with their } \\
\text { results }\end{array}$ \\
\hline $\begin{array}{l}\text { P.K.N. } \\
\text { Anooj } \\
\text { [9] }\end{array}$ & 2011 & $\begin{array}{l}\text { Weighted fuzzy rules } \\
\text { and decision tree } \\
\text { rules }\end{array}$ & $\begin{array}{c}\text { UCI data set, No IoT } \\
\text { Technology }\end{array}$ & Heart disease & MATLAB & $\begin{array}{l}\text { Proposed clinical decision Support System } \\
\text { (CDSS) having better performance as } \\
\text { compared to } \mathrm{n} / \mathrm{w} \text { based system }\end{array}$ & $\begin{array}{c}\text { Sensitivity- } 59.9 \% \\
\text { Specificity- } 68.75 \% \\
\text { Accuracy- } 57.85 \%\end{array}$ \\
\hline $\begin{array}{l}\text { Chiuchisan, } \\
\text { Geman [32] }\end{array}$ & 2014 & $\begin{array}{l}\text { Artificial Neural N/W } \\
\text { (ANN) and Fuzzy } \\
\text { Logic in IoT } \\
\text { environment }\end{array}$ & $\begin{array}{l}\text { Trivial Mouse modified } \\
\text { for hand tremor, } 3 \text { axis } \\
\text { accelerator sensor, } \\
\text { Bluetooth technology }\end{array}$ & $\begin{array}{l}\text { Neurological } \\
\text { Disorder }\end{array}$ & $\begin{array}{l}\text { MySQL, DB } \\
\text { Server, } \\
\text { Microsoft } \\
\text { Visual C }\end{array}$ & $\begin{array}{l}\text { New established system enables patients to } \\
\text { conduct tests on themselves at their home }\end{array}$ & NA \\
\hline $\begin{array}{l}\text { P.D Kaur et } \\
\text { al.[17] }\end{array}$ & 2014 & $\begin{array}{l}\text { K-Nearest Neighbour } \\
(\text { KNN), Naïve Bayes }\end{array}$ & $\begin{array}{l}\text { Bood Pressure Sensor, } \\
\text { Peak Flow sensor, Glucose } \\
\text { meter, and weight scale }\end{array}$ & Diabetes & $\begin{array}{l}\text { WEKA, } \\
\text { MYSQL as } \\
\text { DB server, } \\
\text { Amazon EC2 }\end{array}$ & $\begin{array}{c}\text { Proposed CBIHCS system offers a real-time } \\
\text { monitoring of patient health data, and offers } \\
\text { cost-effective and globally accessible } \\
\text { healthcare system, KNN achieved better } \\
\text { performance in newly established } \\
\text { environment }\end{array}$ & $\begin{array}{c}\text { KNN Accuracy- } \\
92.59 \% \\
\text { NB Accuracy-85.71\% }\end{array}$ \\
\hline Author's Name & Year & $\begin{array}{l}\text { Data Mining } \\
\text { Techniques }\end{array}$ & Sensors / IoT Technology & Diseases & Tools & Findings & $\begin{array}{c}\text { Performance Metrics } \\
\text { with their results }\end{array}$ \\
\hline $\begin{array}{l}\text { Sanjay Sareen } \\
\text { et al.[34] }\end{array}$ & 2016 & $\begin{array}{l}\text { J48, Random Tree, } \\
\text { Naïve Bayes }\end{array}$ & $\begin{array}{l}\text { Blood Pressure sensor, } \\
\text { Temperature sensor, RFID } \\
\text { and Bluetooth technology }\end{array}$ & Ebola Virus & WEKA 3.6 & $\begin{array}{l}\text { Proposed model is able to prevent the } \\
\text { spreading of Ebola virus at an early stage } \\
\text { and J48 decision tree having better } \\
\text { performance in new real-time monitoring } \\
\text { environment }\end{array}$ & $\begin{array}{l}\text { Recall-91.2\%, } \\
\text { Precision- 90\%, } \\
\text { Accuracy-94\%, } \\
\text { Specificity54\% }\end{array}$ \\
\hline $\begin{array}{c}\text { Hossian\& } \\
\text { Muhammad } \\
{[14]}\end{array}$ & 2016 & One class SVM & $\begin{array}{l}\text { MIT-BIH data, EGC } \\
\text { monitoring sensors }\end{array}$ & Heart Disease & NA & $\begin{array}{l}\text { Proposed a cloud-integrated IoT enabled } \\
\text { health monitoring system by using better } \\
\text { security beaches facilitate better care with } \\
\text { reduced cost and time }\end{array}$ & $\begin{array}{l}\text { OSVM achieved } \\
\text { Accuracy- } 87.7 \% \text { with } \\
\text { MIT-BIH data and } \\
90.4 \% \text { with real data }\end{array}$ \\
\hline
\end{tabular}


Navita et al., International Journal of Emerging Trends in Engineering Research, 8(9), September 2020, 6131 - 6138

\begin{tabular}{|c|c|c|c|c|c|c|c|}
\hline $\begin{array}{l}\text { Author's } \\
\text { Name }\end{array}$ & Year & $\begin{array}{c}\text { Data Mining } \\
\text { Techniques }\end{array}$ & Sensors / IoT Technology & Diseases & Tools & Findings & $\begin{array}{l}\text { Performance } \\
\text { Metrics with their } \\
\text { results }\end{array}$ \\
\hline $\begin{array}{l}\text { L. Sayeed et } \\
\text { al. [36] }\end{array}$ & 2017 & $\begin{array}{l}\text { J48, Random Forest } \\
\text { Tree, KNN, } \\
\text { Multilayer Perceptron } \\
\text { Neural N/W }\end{array}$ & $\begin{array}{l}\text { MIAS (Mammographic } \\
\text { Image Analysis society) } \\
\text { data set, Bluetooth }\end{array}$ & $\begin{array}{c}\text { Breast Cancer } \\
\text { Disease }\end{array}$ & $\begin{array}{c}\text { Apache } \\
\text { Mahout, } \\
\text { HBase, Weka }\end{array}$ & $\begin{array}{l}\text { The proposed approach is highly useful for } \\
\text { the physician to detect and analyze the breast } \\
\text { cancer, Decision tree accomplish better } \\
\text { accuracy as compared to other Data Mining } \\
\text { Techniques }\end{array}$ & $\begin{array}{c}\text { Accuracy-96.93\% } \\
\text { Sensitivity-98.13\% } \\
\text { Specificity-79.94\% }\end{array}$ \\
\hline $\begin{array}{l}\text { P. Verma et al. } \\
\text { [27] }\end{array}$ & 2017 & $\begin{array}{l}\text { KNN, Decision Tree, } \\
\text { SVM, Naïve Bayes }\end{array}$ & $\begin{array}{l}\text { ECG Monitor, Heart } \\
\text { sensor, Temperature } \\
\text { sensor, Humidity Sensor, } \\
\text { Chemical detector, noise } \\
\text { sensor, Bluetooth }\end{array}$ & $\begin{array}{l}\text { Water Borne } \\
\text { Disease }\end{array}$ & $\begin{array}{l}\text { MySQL DB, } \\
\text { WEKA, } \\
\text { Amazon EC2 }\end{array}$ & $\begin{array}{l}\text { Proposed methodology is highly supportive } \\
\text { to retrieve time- sensitive information within } \\
\text { the limited time, Decision tree achieved } \\
\text { better performance as compared to other } \\
\text { Data Mining Techniques in IoT environment }\end{array}$ & $\begin{array}{l}\text { Accuracy-92.59\% } \\
\text { Sensitivity-86.87\% } \\
\text { Specificity-79.94\% }\end{array}$ \\
\hline $\begin{array}{l}\text { P.Verma and } \\
\text { S. Sood [24] }\end{array}$ & 2018 & $\begin{array}{c}\text { Decision tree, KNN, } \\
\text { NB, SVM }\end{array}$ & $\begin{array}{l}\text { UCI data, Blood Pressure } \\
\text { sensor, EmotivEpoc } \\
\text { sensor, temperature sensor, } \\
\text { Bluetooth }\end{array}$ & $\begin{array}{l}\text { Hyper-tension } \\
\text { diseases }\end{array}$ & WEKA & $\begin{array}{c}\text { Result obtained are highly useful in } \\
\text { choosing the best classifier for a particular } \\
\text { disease taken into consideration, Decision } \\
\text { tree having superior performance as } \\
\text { compared to other classification techniques } \\
\text { in new environment }\end{array}$ & $\begin{array}{c}\text { Accuracy-92.8\%, } \\
\text { Sensitivity-90.4\% } \\
\text { Specificity-93.3\% } \\
\text { F-Measure-96\% }\end{array}$ \\
\hline $\begin{array}{l}\text { P. Kuma } \\
\text { \&U.Gandhi } \\
\quad[18]\end{array}$ & 2018 & ROC analysis & $\begin{array}{c}\text { SpO2, ECG, Blood } \\
\text { Oxygen, Pulse Oximeter }\end{array}$ & Heart diseases & $\begin{array}{l}\text { HBase, } \\
\text { Apache } \\
\text { Mahout }\end{array}$ & $\begin{array}{l}\text { The proposed model recognize the highly } \\
\text { significant parameters used to identify the } \\
\text { heart diseases }\end{array}$ & $\begin{array}{c}\text { Sensitivity, } \\
\text { Specificity, +ve } \\
\text { Likelihood Ratio } \\
\text { (PLR), -ve } \\
\text { Likelihood Ratio } \\
\text { (NLR), +ve predicted } \\
\text { value(PPV) and -ve } \\
\text { predicted value(NPV) }\end{array}$ \\
\hline Aichet al.[32] & 2018 & $\begin{array}{c}\text { PCA, OSPF for } \\
\text { feature selection, for } \\
\text { classification -RPAT, } \\
\text { C4.5, PART, } \\
\text { Bagging, Regression } \\
\text { Tree, Random Forest }\end{array}$ & $\begin{array}{l}\text { Max Little Univ., } \\
\text { OXFORD }\end{array}$ & Parkinsons & $\mathrm{R}$ & $\begin{array}{l}\text { PCA based feature set perform better with } \\
\text { random forest classifier as compared to the } \\
\text { original feature set and the result of this } \\
\text { analysis helps the physicians to focus } \\
\text { towards important feature for early diagnosis } \\
\text { of Parkinson's disease }\end{array}$ & $\begin{array}{c}\text { Accuracy-92.8\%, } \\
\text { Sensitivity-90.4\% } \\
\text { Specificity-93.3\% } \\
\text { F-Measure-96\% }\end{array}$ \\
\hline
\end{tabular}




\section{CONCLUSION}

With the indulgement of the concept of the IoT in the healthcare domain, the diagnosis process becomes fast, reliable, and more efficient. A large portion of our population suffering from some chronic diseases and they are in need of timely and cost-effective treatment. Data mining techniques play a major role in supporting the IoT system to provide better healthcare services. This paper presents a comparative analysis and a short review on the data mining techniques and algorithms that are greatly significant to process and handle the large amount of data in IoT based smart healthcare environment. The study also says that efficiency of any healthcare system generally depends on the accurate diagnosis of diseases and timely treatment of the patient. From comparative analysis, it can be obviously observed that data mining techniques and algorithms offer improved correctness on various diseases when applied in smart environment. This paper also specifies a set of tools that are developed in community to AI which are helpful for the analysis of similar problems, and different types of sensors used for remote monitoring of patient in smart environment. This paper may be very supportive for the researchers who are currently working in this area and also provides great opportunities for the researchers who want to make further improvements in the existing decision-making process.

\section{REFERENCES}

[1] https://www.ericsson.com/en/mobility-report/internet-ofthings-forecast

[2] https://www.cdc.gov/chronicdisease/about/costs/index.ht $\mathrm{m}$

[3] D. Niewolny,How the Internet of Things Is Revolutionizing Healthcare. Published by Freescale Semiconductors, 18 Oct 2013.

[4] A. Kulkarni, S. R. Sathe, "Healthcare applications of the Internet of Things: A Review", International Journal of Computer Science and Information Technologies (IJCSIT), vol. 5, pp. 6229-6232, 2014.

[5] F. Chen, P. Deng, J. Wan, D. Zhang, A. V. Vasilakos, and $\mathrm{X}$. Rong, "Data Mining for the Internet of Things: Literature Review and Challenges" ,International Journal of Distributed Sensor Networks, vol. 11, no. 8, p. 431-447, Aug. 2015, doi: 10.1155/2015/431047.

[6] C. Tsai, C. Lai, M. Chiang and L. T. Yang, Data Mining for Internet of Things: A Survey.Published in IEEE Communications Surveys \& Tutorials, vol. 16, no. 1, pp. 77-97, First Quarter 2014, doi: 10.1109/SURV.2013.103013.00206.

[7] P. Prajapti, J. Vasa and J. Patel,A Resaerch Directions on Data Mining with IoT. Publsihed inInternational Conference on Information and Communication Technology for Intelligent SystemsICTIS 2017: Information and Communication Technology for Intelligent Systems (ICTIS 2017) -vol. 1, pp 183-190.

[8] F.Alam, R.Mehmood, I.KatibandA.Albeshri, Analysis of Eight Data Mining Algorithms for Smarter Internet of Things (IoT), International Workshop on Data Mining in IoT Systems (DaMIS 2016), Procedia
Computer Science 98, pp. 437 - 442 , 2016 doi:10.1016/j.procs.2016.09.068

[9] P. Anooj, “Clinical decision support system: risk level prediction of heart disease using weighted fuzzy rules and decision tree rules" , Journal of Open Computer Science, vol. 1, no. 4, Jan. 2011, doi: 10.2478/s13537011-0032-y.

[10] T. R. Baitharu and S. K. Pani, Analysis of Data Mining Techniques for Healthcare Decision Support System Using Liver Disorder Dataset. Procedia Computer Science, vol. 85, pp. 862-870, 2016, doi: 10.1016/j.procs.2016.05.276.

[11] S. B. Baker, W. Xiang, and I. Atkinson, "Internet of Things for Smart Healthcare: Technologies, Challenges, and Opportunities", Published in IEEE Access, vol. 5, pp. 26521-26544, 2017, doi: 10.1109/ACCESS.2017.2775180.

[12] H. Banaee, M. Ahmed, and A. Loutfi, "Data Mining for Wearable Sensors in Health Monitoring Systems: A Review of Recent Trends and Challenges", Sensors Journal, vol. 13, no. 12, pp. 17472-17500, 2013, doi: $10.3390 / \mathrm{s} 131217472$.

[13] M. Durairaj and V. Ranjani, "Data Mining Applications In Healthcare Sector: A Study", International Journal of Scientific \& Technology Research, vol. 2, no. 10, 2013.

[14] M. M. Hassan, H. S. Albakr, and H. Al-Dossari, A Cloud-Assisted Internet of Things Framework for Pervasive Healthcare in Smart City Environment, Published in Proceedings of the 1st International Workshop on Emerging Multimedia Applications and Services for Smart Cities - EMASC '14, Orlando, Florida, USA, 2014, pp. 9-13, doi: 10.1145/2661704.2661707.

[15] M. Hassanalieragh et al., Health Monitoring and Management Using Internet-of-Things (IoT) Sensing with Cloud-Based Processing: Opportunities and Challenges.Published in 2015 IEEE International Conference on Services Computing, New York City, NY, USA, pp. 285-292, 2015 doi: 10.1109/SCC.2015.47.

[16] J. Jonnagaddala, S.-T. Liaw, P. Ray, M. Kumar, H.-J. Dai, and C.-Y. Hsu, "Identification and Progression of Heart Disease Risk Factors in Diabetic Patients from Longitudinal Electronic Health Records", BioMed Research International, vol. 2015, pp. 1-10, 2015, doi: 10.1155/2015/636371.

[17] P. D. Kaur and I. Chana, "Cloud based intelligent system for delivering health care as a service", Journal of Computer Methods and Programs in Biomedicine, vol. 113, no. 1, pp. 346-359, Jan. 2014, doi: 10.1016/j.cmpb.2013.09.013.

[18] P.Kumar and U.Gandhi, "A novel three-tier Internet of Things architecture with machine learning algorithm for early detection of heart diseases", Journal of Computers and Electrical Engineering, pp. 222-235,

2018,http://dx.doi.org/10.1016/j.compeleceng.2017.09.001.

[19] M. Marinov, A. S. M. Mosa, I. Yoo, and S. A. Boren, "Data-Mining Technologies for Diabetes: A Systematic Review", Journal of Diabetes Science and Technology, vol. 5, no. 6, pp. 1549-1556, Nov. 2011, 
doi: $10.1177 / 193229681100500631$.

[20] S. M. Riazul Islam, Daehan Kwak, M. Humaun Kabir, M. Hossain, and Kyung-Sup Kwak, "The Internet of Things for Health Care: A Comprehensive Survey", IEEE Access, vol. 3, pp. 678-708, 2015, doi: 10.1109/ACCESS.2015.2437951.

[21] C. S.Dangare and S. S. Apte, "Improved Study of Heart Disease Prediction System using Data Mining Classification Techniques", International Journal of Computer Appications (IJCA), vol. 47, no. 10, pp. 44-48, Jun. 2012, doi: 10.5120/7228-0076.

[22] K. Subhadra, "Neural Network Based Intelligent System for Predicting Heart Disease", International Journal of Innovative Technology and Exploring Engineering (IJITEE), vol. 8, no. 5, p. 4, 2019.

[23] L. Syed, S. Jabeen, S. Manimala, and H. A. Elsayed, "Data Science Algorithms and Techniques for Smart Healthcare Using IoT and Big Data Analytics" ,Published in Journal of Smart Techniques for a Smarter Planet, vol. 374, Springer International Publishing, pp. 211-241, 2019.

[24] P. Verma and S. K. Sood, "Cloud-centric IoT based disease diagnosis healthcare framework", Journal of Parallel and Distributed Computing, vol. 116, pp. 27-38, Jun. 2018, doi: 10.1016/j.jpdc.2017.11.018.

[25] H. Yin and N. K. Jha, "A Health Decision Support System for Disease Diagnosis Based on Wearable Medical Sensors and Machine Learning Ensembles",Published by IEEE Trans. Multi-Scale Comp. Syst., vol. 3, no. 4, pp. 228-241, Oct. 2017, doi: 10.1109/TMSCS.2017.2710194.

[26] P. verma,S.K. Sood andS.Kalra, “Cloud $\square$ centric IoT based student healthcare monitoring framework",Journal of Ambient Intelligence and Humanized Computing (JAIHC), vol. 9, pp. 1293-1309, 2017.

[27] M. Marinov, A.S.Mohammad, I.Yo and S.A.Boren, "Data-Mining Technologies for Diabetes : A Systematic Review", 2011.

[28] M. Fatima and M. Pasha, "Survey of Machine Learning Algorithms for Disease Diagnostic",Journal of Intelligent Learning Systema and Applications JILSA, vol. 09, no. 01, pp. 1-16, 2017, doi: 10.4236/jilsa.2017.91001.

[29] G. J. Joyia, R. M. Liaqat, A. Farooq, and S. Rehman, "Internet of Medical Things (IOMT): Applications, Benefits and Future Challenges in Healthcare Domain", Journal of Clinical Microbiology, 2017, doi: 10.12720/jcm.12.4.240-247.

[30] J. Wan et al., "Wearable IoT enabled real-time health monitoring system", Journal of Wireless Computer Network, no. 1, p. 298, Dec. 2018, doi: 10.1186/s13638-018-1308-x.

[31] Chiuchisan andGeman, "An Approach of a Decision Support and Home Monitoring System for Patients with Neurological Disorders using Internet of Things Concepts", Wseas Transactions On Systems, vol.13,
2014.

[32] S. Aich, K.Younga, K.L.Hui, A.Absi and M. Sain, A Nonlinear Decision Tree based Classification Approach to Predict the Parkinson's disease using Different Feature Sets of Voice Data. Published inInternational Conference on Advanced Communications Technology(ICACT), pp. 638-642, 2018.

[33] Sanjay Sareen, "IoT based cloud framework to control Ebola Virus outbreak", Journal of Ambient Intelligent and Humanized Computing vol. 9, pp. 459476, 2016.

[34] M. Ganesan and N. Sivakumar,IoT based heart disease prediction and diagnosis model for healthcare using machine learning models, IEEE International Conference on System, Computation, Automation and Networking (ICSCAN), 2019.

[35] P. M. Kumar, S. Lokesh, R. Varatharajan, G. Chandra Babu, and P. Parthasarathy, "Cloud and IoT based disease prediction and diagnosis system for healthcare using Fuzzy neural classifier" ,Journal of Future Generation Computer Systems, vol. 86, pp. 527-534, Sep. 2018, doi: 10.1016/j.future.2018.04.036.

[36] L.Syed, S. Jabeen and S. Manimala, "Telemammography: A Novel Approach for Early Detection of Breast Cancer Through Wavelets Based Image Processing and Machine Learning Techniques" , Published in Advances in Soft Computing and Machine Learning in Image Processing by Springer, 2018,https://doi.org/10.1007/978-3-319-63754-9_8.

[37] K.Sumathi ,K.Naveena ,P.Prashanth ,S.RevanthKumar,A.P.Srikeerthanaa," E-Health based Patient Surveilling Device" International Journal of Emerging Trends in Engineering Research (IJETER), vol. 8, No. 3, March 2020.https://doi.org/10.30534/ijeter/2020/30832020

[38] Aaron Don M. Africa, Bryon Gil Cajayon, Adrian Alano,"IoT Technologies Systems on Medical Monitoring and Management Systems with a RealTime ECG Signal Transmission Monitoring Algorithm", International Journal of Emerging Trends in Engineering Research (IJETER), vol. 8, No. 5, May 2020.

https://doi.org/10.30534/ijeter/2020/69852020

[39] Deepti Rani and Nasib Singh Gill, "Lightweight Security Protocols for Internet of Things: A Review", International Journal of Advanced Trends in Computer Science and Engineering (IJATCSE), Volume 8, No.3, May - June 2019, pp. 707-719.

[40] https://www.google.com/search?q=biomedical+sensor s\&rlz=1C1CHWA_enIN901IN901\&sxsrf=ALeKk00sRu TB8H7oyRokjrLzAIyCtOYxQA:1591708831281\&sourc $\mathrm{e}=$ lnms\&tbm=isch\&sa=X\&ved=2ahUKEwiQtuW76fTp AhWPILcAHchZDbEQ_AUoAXoECBQQAw\&biw=13 $66 \&$ bih $=657 \#$ imgrc $=\mathrm{mT3}$ WO6Sn70IF4M\&imgdii $=\mathrm{c} 4 \mathrm{G}$ Wr2Uq2zZaMM 